\title{
Total Antioxidant Status in Type 2 Diabetic Patients in Palestine
}

\author{
Akram T. Kharroubi, ${ }^{1}$ Hisham M. Darwish, ${ }^{2}$ Mutaz A. Akkawi, ${ }^{3}$ Abdelkareem A. Ashareef, ${ }^{3}$ \\ Zaher A. Almasri, ${ }^{3}$ Khaldoun A. Bader, ${ }^{4}$ and Umaiyeh M. Khammash ${ }^{5}$ \\ ${ }^{1}$ Department of Medical Laboratory Sciences, Faculty of Health Professions, Al-Quds University, Jerusalem, State of Palestine \\ ${ }^{2}$ Department of Biochemistry, Faculty of Medicine, Al-Quds University, Jerusalem, State of Palestine \\ ${ }^{3}$ Department of Biological Sciences, Faculty of Science and Technology, Al-Quds University, Jerusalem, State of Palestine \\ ${ }^{4}$ Faculty of Public Health, Al-Quds University, Jerusalem, State of Palestine \\ ${ }^{5}$ United Nation Relief and Works Agency (UNRWA), Jerusalem, State of Palestine
}

Correspondence should be addressed to Akram T. Kharroubi; akram.kharroubi@gmail.com

Received 9 January 2015; Revised 11 May 2015; Accepted 12 May 2015

Academic Editor: Carlos Martinez Salgado

Copyright (C) 2015 Akram T. Kharroubi et al. This is an open access article distributed under the Creative Commons Attribution License, which permits unrestricted use, distribution, and reproduction in any medium, provided the original work is properly cited.

\begin{abstract}
The objective of this study was to compare the level of total antioxidant status (TAS) in type 2 diabetic and normal Palestinian subjects as well as the major factors influencing TAS levels. A sample of convenience composed of 212 type 2 diabetic and 208 normal subjects above the age of 40 were recruited. Only $9.8 \%$ of the subjects had normal body mass index (BMI) levels (<25), $29 \%$ were overweight $(\geq 25$ to $<30)$, and $61.2 \%$ were obese $(\geq 30)$. The mean levels of TAS were significantly higher in diabetic compared to control subjects ( 2.18 versus $1.84 \mathrm{mM}$ Trolox, $P=0.001$ ) and in hypertensive subjects compared to subjects with normal blood pressure (BP). Mean TAS levels were higher in obese compared to nonobese subjects (2.12 versus $1.85 \mathrm{mM}$ Trolox, $P=0.001)$. Mean TAS levels were similarly higher in subjects with high fasting plasma glucose (FPG) compared to normal FPG (2.19 versus $1.90 \mathrm{mM}$ Trolox) and high HbAlc $(\geq 6.5 \%)$ compared to HbAlc $<6.5 \%$ (2.14 versus $1.91 \mathrm{mM}$ Trolox). Multivariate analysis revealed that only diabetic status $(P=0.032)$ and the level of education $(P=0.036)$ were significantly associated with TAS. In conclusion diabetic patients had $18.5 \%$ increase in TAS levels compared to control subjects.
\end{abstract}

\section{Introduction}

The prevalence of diabetes in the Middle East countries is among the highest in the world $[1,2]$. The prevalence of diabetes among the Palestinian population is about $12 \%[3$, 4] compared with the highest (about 20\%) in the United Arab Emirates [5,6]. Four of the top ten countries with the highest prevalence of prediabetes are in the Middle East Arab states of the Gulf (Kuwait, Qatar, United Arab Emirates (UAE), and Bahrin with prevalence of $17.9 \%, 17.1 \%, 16.6 \%$, and $16.3 \%$, resp.) [2]. Risk factors for type 2 diabetes mellitus among the Palestinian community including obesity, genetic predisposition, and sedentary life style are clearly evident [7]. Oxidative stress, defined as excess formation and/or insufficient removal of highly reactive molecules such as reactive oxygen species (ROS) and reactive nitrogen species (RNS), increases in diabetes when free radical production exceeds the body's ability to neutralize them $[8,9]$. Excess generation of free radicals has been associated with tissue damage and complications in diabetic patients [10-19].

Despite the agreement on the increase of free radicals in diabetic patients, the level of antioxidants in diabetic patients has been reported to decrease [20-25], increase [26-28], or stay the same [10]. The effect of diabetes on total antioxidant levels seems to be complicated by the effect of diabetes on individual antioxidant systems. Kimura et al. [27] reported an increase in extracellular superoxide dismutase (SOD) whereas Palanduz et al. [29] reported a decrease in plasma glutathione peroxidase levels and an increase in plasma SOD at the same time. Al-Rawi [30] also reported an increase in SOD in diabetic patients in the UAE.

In this study we investigated for the first time the association of TAS in Palestinian type 2 diabetic subjects with several environmental and biochemical parameters known to affect or be affected by diabetes. 


\section{Materials and Methods}

2.1. Participants. A sample of convenience composed of 209 known type 2 diabetic patients treated at UNRWA clinics for diabetes (70 males and 139 females) and 208 known normal subjects (68 males and 140 females) above the age of 40 were recruited from three major central clinics in the West Bank administered by UNRWA. Seventy-six out of the 208 normal subjects have impaired fasting plasma glucose $(\geq 5.6$ to $<7.0 \mathrm{mmol} / \mathrm{L}$ ). All subjects were instructed to fast for $10-$ 12 hours before coming to the clinics at 8:00 am. A special questionnaire designed to collect sociodemographic, lifestyle, family history, and health related information was filled for all participants during direct interviews with the researchers. Subjects who administered antioxidants as supplements like vitamins were excluded from the study. Diabetic subjects were on different medications, mainly metformin. Those who were on insulin were excluded from the study. Blood pressure (BP), weight, and height were measured by the medical teams in the clinics. Body mass index (BMI) in $\mathrm{kg} / \mathrm{m}^{2}$ was categorized as normal (BMI $<25)$, overweight $(\mathrm{BMI} \geq 25$ to $<30)$, and obese $(B M I \geq 30)$. Diabetic subjects were not on special diets. The study protocol was approved by AlQuds University and UNRWA ethical committees and all participants gave their informed consent.

2.2. Analytical Procedures. Blood samples were collected from all subjects and were tested for their total antioxidant status (TAS), fasting plasma glucose (FPG), glycated hemoglobin (HbAlc), and total lipid profile including total cholesterol (TC), triacylglycerol (TG), low density lipoprotein-cholesterol (LDL-C), and high density lipoprotein-cholesterol (HDL-C). Serum for TAS analysis was separated using refrigerated centrifuge under dim light and kept frozen at $-80^{\circ} \mathrm{C}$ for two weeks before analysis.

The antioxidant activity was measured as the ability of the serum to prevent ABTS oxidation in comparison to Trolox and quantified as millimolar Trolox equivalents using antioxidant assay kits (Cayman Chemical Co., Ann Arbor, MI, USA). Glycated hemoglobin was measured by boronate affinity assay using NycoCard HbAlc Kit (Axisshield, Oslo, Norway) that reports a standardized HbAlc value according to IFCC recommendations. Fasting plasma glucose and total lipid profile (TC, TG, and HDL) were measured enzymatically using Chemwell chemistry analyzer (Awareness Tech, USA), and LDL-C was calculated from the equation of Friedewald (LDL-C $=$ TC - [HDL-C + (TG/5)]). The FPG results were categorized as normal (FPG $<100 \mathrm{mg} / \mathrm{dL}$ ), impaired (FPG 100-125 mg/dL), and diabetic (FPG $\geq 126 \mathrm{mg} / \mathrm{dL})$.

2.3. Statistical Analysis. Statistical analysis was performed using SPSS 17.0 software (SPSS Inc., Chicago, IL, USA). Pearson's correlation coefficient was used to test for colinearity between the continuous variables; statistical comparisons between different groups for these continuous variables were carried out using Student's $t$-test and ANOVA and Pearson's chi-square statistic was used to assess relationships between
TABLE 1: Comparison between diabetic and control subjects with regard to different parameters.

\begin{tabular}{lccc}
\hline Parameter & $\begin{array}{c}\text { Mean } \pm \text { STD } \\
\text { Control }\end{array}$ & $\begin{array}{c}\text { Mean } \pm \text { STD } \\
\text { Diabetic }\end{array}$ & $P$ \\
\hline Age (years) & $50.0 \pm 9.40$ & $55.0 \pm 8.31$ & 0.001 \\
Systolic BP (mm Hg) & $125 \pm 16.8$ & $135 \pm 16.9$ & 0.001 \\
Diastolic BP (mm Hg) & $77.5 \pm 13.8$ & $80.4 \pm 12.3$ & 0.021 \\
FPG mmol/L & $5.31 \pm 0.83$ & $10.3 \pm 4.26$ & 0.001 \\
HbAlc $(\%)$ & $5.75 \pm 0.62$ & $8.14 \pm 1.74$ & 0.001 \\
BMI & $31.1 \pm 6.92$ & $33.3 \pm 6.18$ & 0.001 \\
TC mmol/L & $5.12 \pm 1.04$ & $5.30 \pm 1.07$ & 0.089 \\
TG mmol/L & $1.58 \pm 1.34$ & $2.20 \pm 1.34$ & 0.001 \\
HDL mmol/L & $1.25 \pm 0.37$ & $1.09 \pm 0.23$ & 0.001 \\
LDL calculated mmol/L & $3.19 \pm 0.85$ & $3.24 \pm 0.98$ & 0.68 \\
LDL direct mmol/L & $3.03 \pm 1.05$ & $3.26 \pm 1.10$ & 0.046 \\
\hline
\end{tabular}

FPG: fasting plasma glucose; TC: total cholesterol; TG: triglycerides; HDL: high density lipoprotein; LDL: low density lipoprotein, BMI: body mass index; HbAlc: hemoglobin Alc.

categorical variables. Multivariate analysis implementing general linear model (ANCOVA) was performed to adjust and control potential confounders and to test for interactions between the variables that appeared significantly associated with the independent variable (TAS) in the bivariate analysis. Statistical significance was accepted at $P<0.05$. Because of missing values the number of each group in different comparisons is different.

\section{Results}

Table 1 shows that mean FPG and HbAlc in diabetic subjects were higher than controls (10.3 versus $5.31 \mathrm{mmol} / \mathrm{L}$ for FPG and 8.14 versus $5.75 \%$ for HbAlc, resp.). Evidently, the mean systolic and diastolic BP were significantly higher in diabetic compared to normal subjects (Table 1). In addition, the mean triacylglycerol levels were higher whereas HDL levels were significantly lower in diabetics compared to normal subjects. Table 1 also shows that BMI for both diabetic and control subjects was above 30 which indicates that control and diabetic subjects were both obese. Diabetic subjects had significantly higher mean BMI compared to control subjects (33.3 versus 31.1, resp.). Only $9.8 \%$ of the subjects had normal BMI levels whereas $29 \%$ were overweight and $61.2 \%$ were obese. In our study, subjects with high systolic BP $(\geq 140 \mathrm{~mm} \mathrm{Hg})$ constitute $31.6 \%$ whereas those with high diastolic BP ( $\geq 90 \mathrm{~mm} \mathrm{Hg}$ ) constitute $24.8 \%$. Furthermore, subjects with abnormal lipid profile including high TC ( $\geq 5.5 \mathrm{mmol} / \mathrm{L})$, high TG $(\geq 2.0 \mathrm{mmol} / \mathrm{L})$, and high LDL $(\geq 3.5 \mathrm{mmol} / \mathrm{L})$ represented $35.0 \%, 31.9 \%$, and $33.6 \%$, respectively, whereas subjects with low $\mathrm{HDL}(<1.0 \mathrm{mmol} / \mathrm{L})$ represented $26.6 \%$ of the entire subjects in the study. Moreover, subjects with family history for diabetes or family history for cardiovascular disease (CVD) were $59 \%$ and $46 \%$ of all the studied subjects, respectively. Our data showed that $64 \%$ of subjects with family history for diabetes also developed diabetes compared to $31 \%$ for those subjects with no such family history for diabetes 
TABLE 2: Comparison between mean values of total antioxidants status (TAS) with respect to different parameters.

\begin{tabular}{|c|c|c|c|}
\hline Parameter & & $\begin{array}{l}\text { TAS (mM Trolox) } \\
\text { Mean } \pm \text { STD }(N)\end{array}$ & $P$ \\
\hline \multirow{2}{*}{ Gender } & Male & $2.00 \pm 0.79(128)$ & \multirow{2}{*}{0.660} \\
\hline & Female & $2.04 \pm 0.80(253)$ & \\
\hline \multirow{2}{*}{ Diabetic status } & Diabetic & $2.18 \pm 0.86(206)$ & \multirow{2}{*}{0.000} \\
\hline & Control & $1.84 \pm 0.67(175)$ & \\
\hline \multirow{2}{*}{ Systolic blood pressure (mm Hg) } & $<140 \mathrm{~mm} \mathrm{Hg}$ & $1.97 \pm 0.78(261)$ & \multirow{2}{*}{0.047} \\
\hline & $\geq 140 \mathrm{~mm} \mathrm{Hg}$ & $2.15 \pm 0.83(118)$ & \\
\hline \multirow{2}{*}{ Diastolic blood pressure $(\mathrm{mm} \mathrm{Hg})$} & $<90 \mathrm{~mm} \mathrm{Hg}$ & $1.96 \pm 0.79(285)$ & \multirow{2}{*}{0.006} \\
\hline & $\geq 90 \mathrm{~mm} \mathrm{Hg}$ & $2.22 \pm 0.81(94)$ & \\
\hline \multirow{2}{*}{ Total cholesterol (mmol/L) } & $<5.5 \mathrm{mmol} / \mathrm{L}$ & $2.01 \pm 0.77(254)$ & \multirow{2}{*}{0.745} \\
\hline & $\geq 5.5 \mathrm{mmol} / \mathrm{L}$ & $2.04 \pm 0.84(127)$ & \\
\hline \multirow{2}{*}{$\mathrm{HDL}(\mathrm{mmol} / \mathrm{L})$} & $<1.0 \mathrm{mmol} / \mathrm{L}$ & $2.02 \pm 0.78(107)$ & \multirow{2}{*}{0.959} \\
\hline & $\geq 1.0 \mathrm{mmol} / \mathrm{L}$ & $2.02 \pm 0.80(274)$ & \\
\hline \multirow{2}{*}{ LDL calculated (mmol/L) } & $<3.5 \mathrm{mmol} / \mathrm{L}$ & $2.02 \pm 0.80(260)$ & \multirow{2}{*}{0.878} \\
\hline & $\geq 3.5 \mathrm{mmol} / \mathrm{L}$ & $2.03 \pm 0.80(121)$ & \\
\hline \multirow{2}{*}{$\mathrm{LDL}$ direct $(\mathrm{mmol} / \mathrm{L})$} & $<3.5 \mathrm{mmol} / \mathrm{L}$ & $2.01 \pm 0.80(252)$ & \multirow{2}{*}{0.752} \\
\hline & $\geq 3.5 \mathrm{mmol} / \mathrm{L}$ & $2.04 \pm 0.79(129)$ & \\
\hline \multirow{2}{*}{$\mathrm{TG}(\mathrm{mmol} / \mathrm{L})$} & $<2.0 \mathrm{mmol} / \mathrm{L}$ & $2.02 \pm 0.78(261)$ & \multirow{2}{*}{0.835} \\
\hline & $\geq 2.0 \mathrm{mmol} / \mathrm{L}$ & $2.02 \pm 0.78(120)$ & \\
\hline \multirow{3}{*}{ BMI $\left(\mathrm{kg} / \mathrm{m}^{2}\right)$} & $<25$ (normal) & $2.15 \pm 0.59(33)^{*}$ & \multirow{3}{*}{0.000} \\
\hline & $\geq 25$ to $<30$ (overweight) & $1.78 \pm 0.70(113)^{* *}$ & \\
\hline & $>30$ (obese) & $2.12 \pm 0.84(235)^{*}$ & \\
\hline \multirow{2}{*}{ HbAlc (\%) } & $<6.5 \%$ & $1.91 \pm 0.71(194)$ & \multirow{2}{*}{0.005} \\
\hline & $\geq 6.5 \%$ & $2.14 \pm 0.87(180)$ & \\
\hline \multirow{2}{*}{$\mathrm{FPG}(\mathrm{mmol} / \mathrm{L})$} & $<7.0 \mathrm{mmol} / \mathrm{L}$ & $1.90 \pm 0.74(220)$ & \multirow{2}{*}{0.000} \\
\hline & $\geq 7.0 \mathrm{mmol} / \mathrm{L}$ & $2.19 \pm 0.85(161)$ & \\
\hline \multirow{3}{*}{ Smoking } & Current smoker & $1.99 \pm 0.82(58)$ & \multirow{3}{*}{0.782} \\
\hline & Former smoker & $1.96 \pm 0.87(35)$ & \\
\hline & Never smoker & $2.04 \pm 0.79(281)$ & \\
\hline \multirow{3}{*}{ FPG $(\mathrm{mmol} / \mathrm{L})$} & Normal & $1.80 \pm 0.75(106)^{*}$ & \\
\hline & Impaired FPG & $1.92 \pm 0.55(70)^{*}$ & 0.000 \\
\hline & Diabetic & $2.17 \pm 0.87(205)^{* *}$ & \\
\hline & Illiterate & $2.09 \pm 0.76(69)^{*}$ & \\
\hline Educational status & Less than high school & $2.11 \pm 0.83(199)^{*}$ & 0.007 \\
\hline & High school & $1.96 \pm 0.71(51)$ & \\
\hline & Diploma and above & $1.72 \pm 0.73(62)^{* *}$ & \\
\hline Family history for diabetes & Present & $2.08 \pm 0.84(227)$ & 0.049 \\
\hline raminy mistory lor uavetes & Absent & $1.92 \pm 0.71(151)$ & 0.049 \\
\hline Family history for CVD & Present & $2.11 \pm 0.86(168)$ & 0.048 \\
\hline Family nistory for C VD & Absent & $1.94 \pm 0.73(207)$ & 0.048 \\
\hline
\end{tabular}

$(P=0.001)$. However, the percentage of subjects who developed diabetes with family history for CVD did not significantly differ between diabetic and control subjects $(51 \%$ versus $48 \%, P=0.298)$. As expected, obesity was positively associated with the diabetes where $58 \%$ of obese subjects had diabetes compared to $38 \%$ of nonobese individuals $(P=$ 0.001).

Table 2 shows that the mean levels of TAS are significantly higher in diabetic subjects compared to control subjects (2.18 versus $1.84 \mathrm{mM}$ Trolox resp., $P=0.001)$. Mean TAS 
levels were also significantly higher in hypertensive subjects (systolic $\mathrm{BP} \geq 140 \mathrm{~mm} \mathrm{Hg}$ or diastolic $\mathrm{BP} \geq 90$ ) compared to subjects with normal BP (systolic $<140 \mathrm{~mm} \mathrm{Hg}$ or diastolic $\mathrm{BP}<90 \mathrm{~mm} \mathrm{Hg}$ ). In addition obese subjects had higher mean TAS levels compared to nonobese subjects (normal and overweight) $[2.12 \pm 0.84$ versus $1.85 \pm 0.70 \mathrm{mM}$ Trolox resp., $P=0.001$ ]. Mean TAS levels were also similarly higher in subjects with high FPG (FPG $\geq 7.0 \mathrm{mmol} / \mathrm{L}$ ) and HbAlc $(\mathrm{HbAlc} \geq 6.5)$. Evidently, subjects with family history for diabetes or family history for CVD had significantly higher mean levels of TAS compared to subjects without family history for diabetes or CVD. In our study, the abnormal lipid profile among diabetic subjects does not seem to affect TAS levels since subjects with abnormal lipid profile had no significant difference in TAS levels compared to subjects with normal lipid profile (Table 2). Our diabetic subjects had higher mean age compared to normal subjects ( 55 versus 50 , $P=0.001$ ). However, when a subset group of 148 subjects with similar age were taken $(51.5 \pm 5.43$ years for diabetic subjects and $51.8 \pm 9.13$ years for control subjects), the mean levels of TAS in diabetic subjects maintained a significantly higher value compared to control subjects $(2.19 \pm 0.85$ versus $1.86 \pm 0.65, P=0.001$, resp.). In addition, diabetic subjects had significantly higher mean TAS levels than controls within the obese and overweight groups (2.24 versus $1.95 \mathrm{mM}$ Trolox within the obese and 1.99 versus $1.59 \mathrm{mM}$ Trolox within the overweight subjects, resp.). The educational level seems to significantly affect TAS levels since subjects with higher educational levels (diploma and above) had lower mean TAS levels compared to subjects with lower educational level (less than high school and including illiterates) (1.72 versus 2.09, $P=0.007$, resp.) This is consistent with the association of educational level with developing diabetes, where only $28 \%$ of subjects with higher education level (diploma and above) had diabetes compared to $64 \%$ for the illiterate $(P=0.001)$.

Using Pearson's correlation coefficients, Table 3 shows significant relationships between TAS levels and the indicated parameters related to diabetes including FPG $(r=0.129$, $P=0.012)$, HbAlc $(r=0.156, P=0.002$,$) , BMI$ $(r=0.117, P=0.022)$, and systolic BP $(r=0.1$, $P=0.019)$. However, when multivariate analysis was performed between TAS as an independent variable and all parameters that were significantly associated with it in the univariate analysis (Table 4), the results revealed that the only parameters that remained to have significant association with TAS were diabetic status $(P=0.032)$ and level of education $(P=0.036)$.

\section{Conclusions}

The implications of increased free radicals and oxidative stress in the development, pathogenesis, and complications of diabetes mellitus [11, 12, 31, 32] and CVD [33] are very strong and well documented despite the inconsistency of the clinical trials using antioxidants in the treatment regimens of diabetes [33-38]. In this study several variables were detected to have an association with the TAS level at the univariate level.
Diabetic subjects had $18.5 \%$ increase in TAS levels compared to controls.

The effect of diabetes duration on antioxidant levels represents another subject of controversy. In our study, at the univariate level of analysis there was a slight negative correlation between TAS levels and years of diabetes $(r=-140)$; however this decrease is not statistically significant. Whiting et al. [39] reported a decrease in the levels of antioxidants in diabetic subjects after 4-6 years of illness while no effect was observed in two years or less. Whether complications of the disease are correlated with the levels of antioxidants is not clear. Opara et al. [22] reported a decrease in antioxidant levels in diabetic subjects with complications while Srivatsan et al. [28] found an increase in antioxidant levels in diabetic subjects without complications. Most diabetic subjects in our study seem to have no obvious complications which is consistent with the notion that the increase in free radicals seems to be associated first with an increase in antioxidant levels and with the progression of the disease the antioxidant levels decrease and complications eventually develop.

The observed significant correlation between TAS with several continuous variables, like systolic BP, FPG, HbAlc, and BMI $(r=0.120,0.129,0.156$, and 0.117, resp.), and noncontinuous variables including education, family history of diabetes, and CVD is relatively not very strong and seems to be mediated through diabetes. This is evident by the multivariate analysis which revealed only diabetes and education to be statistically significant while the effect of education on TAS may also be through diabetes. The multivariate model with these two variables detected as the significant determinants of TAS could have explained about $10 \%$ of the variability in TAS levels. This suggests that other determinants might be involved including genetic and environmental factors. It is not clear in our study whether the effect of diabetes on TAS is influenced by the nutritional habits of participating subjects, since fresh vegetables and fruits are major components of the Palestinian food and food is known to affect antioxidant levels [20, 40-43]. The effect of nutritional status on TAS in the Palestinian society needs to be independently evaluated in future studies. One apparent complication in the interpretation of the obtained results in this study is the fact that more than $90 \%$ of the participating subjects are either overweight or obese. However, when TAS levels were normalized for BMI, the effect of diabetes on TAS still showed diabetic subjects to have higher levels of TAS which suggest that obesity does not seem to be a primary determinant of the antioxidant status of individuals. It is unlikely that the effect of diabetes on TAS levels is due to medications even though this could not be excluded from this study. Changes of dietary habits of diabetic subjects if present could also affect their TAS levels. It is obvious however that regardless of the effect of diabetes on the levels of antioxidant status, the increase in antioxidant levels in diabetic subjects seems to initially reflect adaptation to high free radicals and the decrease in antioxidant levels apparently reflects high and overwhelming levels of free radicals which eventually may play an important role in the development of diabetes complications. Therefore, under all circumstances, the health benefits of reducing the levels of free radicals by 
TABLE 3: Correlation analysis matrix showing covariability between the study continuous variables.

\begin{tabular}{|c|c|c|c|c|c|c|c|c|c|c|c|c|}
\hline & $\begin{array}{c}\text { Age } \\
\text { (years) }\end{array}$ & $\begin{array}{l}\text { Systolic BP } \\
(\mathrm{mm} \mathrm{Hg})\end{array}$ & $\begin{array}{c}\text { Diastolic BP } \\
(\mathrm{mm} \mathrm{Hg})\end{array}$ & $\begin{array}{c}\text { FPG } \\
\mathrm{mmol} / \mathrm{L}\end{array}$ & $\begin{array}{c}\text { HbAlc } \\
(\%)\end{array}$ & $\begin{array}{c}\mathrm{TC} \\
\mathrm{mmol} / \mathrm{L}\end{array}$ & $\begin{array}{c}\mathrm{TG} \\
\mathrm{mmol} / \mathrm{L}\end{array}$ & $\begin{array}{c}\mathrm{HDL} \\
\mathrm{mmol} / \mathrm{L}\end{array}$ & $\begin{array}{c}\mathrm{LDL} \\
\mathrm{mmol} / \mathrm{L}\end{array}$ & BMI & $\begin{array}{c}\mathrm{DM} \\
\text { years }\end{array}$ & TAS \\
\hline \multicolumn{13}{|c|}{ Age (years) } \\
\hline$r$ & 1 & & & & & & & & & & & \\
\hline \multicolumn{13}{|l|}{$p$} \\
\hline \multicolumn{13}{|c|}{ Systolic BP (mm Hg) } \\
\hline$r$ & $0.267^{* *}$ & 1 & & & & & & & & & & \\
\hline$p$ & 0.000 & & & & & & & & & & & \\
\hline \multicolumn{13}{|c|}{ Diastolic BP (mm Hg) } \\
\hline$r$ & $0.111^{*}$ & $0.582^{* *}$ & 1 & & & & & & & & & \\
\hline$p$ & 0.024 & 0.000 & & & & & & & & & & \\
\hline \multicolumn{13}{|c|}{ FPG mmol/L } \\
\hline$r$ & $0.143^{* *}$ & $0.127^{* *}$ & $0.106^{*}$ & 1 & & & & & & & & \\
\hline$p$ & 0.004 & 0.009 & 0.031 & & & & & & & & & \\
\hline \multicolumn{13}{|c|}{ HbAlc (\%) } \\
\hline$r$ & $0.204^{* *}$ & $0.234^{* *}$ & $0.151^{* *}$ & $0.776^{* *}$ & 1 & & & & & & & \\
\hline$p$ & 0.000 & 0.000 & 0.002 & 0.000 & & & & & & & & \\
\hline \multicolumn{13}{|c|}{$\mathrm{TC} \mathrm{mmol} / \mathrm{L}$} \\
\hline$r$ & $0.102^{*}$ & $0.171^{* *}$ & $0.108^{*}$ & $0.127^{* *}$ & $0.132^{* *}$ & 1 & & & & & & \\
\hline$p$ & 0.038 & 0.000 & 0.027 & 0.009 & 0.008 & & & & & & & \\
\hline \multicolumn{13}{|c|}{$\mathrm{TG} \mathrm{mmol} / \mathrm{L}$} \\
\hline$r$ & 0.057 & $0.150^{* *}$ & $0.114^{*}$ & $0.178^{* *}$ & $0.220^{* *}$ & $0.348^{* *}$ & 1 & & & & & \\
\hline$p$ & 0.244 & 0.002 & 0.020 & 0.000 & 0.000 & 0.000 & & & & & & \\
\hline \multicolumn{13}{|c|}{$\mathrm{HDL} \mathrm{mmol} / \mathrm{L}$} \\
\hline$r$ & 0.015 & 0.051 & 0.033 & $-0.156^{* *}$ & $-0.172^{* *}$ & $0.260^{* *}$ & $-0.238^{* *}$ & 1 & & & & \\
\hline$p$ & 0.763 & 0.301 & 0.503 & 0.001 & 0.000 & 0.000 & 0.000 & & & & & \\
\hline \multicolumn{13}{|c|}{$\mathrm{LDL} \mathrm{mmol} / \mathrm{L}$} \\
\hline$r$ & 0.069 & 0.036 & 0.032 & $0.099^{*}$ & 0.067 & $0.845^{* *}$ & -0.013 & $0.194^{* *}$ & 1 & & & \\
\hline$p$ & 0.170 & 0.472 & 0.518 & 0.048 & 0.187 & 0.000 & 0.798 & 0.000 & & & & \\
\hline \multicolumn{13}{|c|}{ BMI } \\
\hline$r$ & -0.030 & 0.092 & $0.146^{* *}$ & $0.101^{*}$ & 0.090 & -0.029 & 0.033 & -0.012 & -0.046 & 1 & & \\
\hline$p$ & 0.539 & 0.060 & 0.003 & 0.040 & 0.070 & 0.560 & 0.505 & 0.809 & 0.362 & & & \\
\hline \multicolumn{13}{|c|}{ DM years } \\
\hline$r$ & $0.285^{* *}$ & 0.133 & 0.059 & $0.312^{* *}$ & $0.408^{* *}$ & -0.067 & 0.070 & -0.016 & -0.119 & $-0.245^{* *}$ & 1 & \\
\hline$p$ & 0.000 & 0.064 & 0.414 & 0.000 & 0.000 & 0.351 & 0.332 & 0.820 & 0.108 & 0.001 & & \\
\hline \multicolumn{13}{|l|}{ TAS } \\
\hline$r$ & 0.085 & $0.120^{*}$ & 0.050 & $0.129^{*}$ & $0.156^{* *}$ & -0.008 & -0.054 & 0.055 & 0.033 & $0.117^{*}$ & -0.140 & 1 \\
\hline$p$ & 0.100 & 0.019 & 0.334 & 0.012 & 0.002 & 0.876 & 0.296 & 0.286 & 0.527 & 0.022 & 0.055 & \\
\hline
\end{tabular}

$r$ = Pearson coefficient; ${ }^{* *} P<0.01$ level (two-tailed); ${ }^{*} P<0.05$ level (two-tailed). FPG: fasting plasma glucose; HDL: high density lipoprotein; LDL: low density lipoprotein; TC: total cholesterol; TG: triglycerides; BMI: body mass index; HbAlc: hemoglobin Alc; DM: diabetes mellitus.

changing dietary habits and supplementation of antioxidant like vitamins in diabetic and nondiabetic subjects should receive more careful evaluation.

\section{Conflict of Interests}

No potential conflict of interests relevant to this paper was reported.

\section{Authors' Contribution}

Akram T. Kharroubi researched data, performed data analysis, and wrote the paper. Hisham M. Darwish researched data and reviewed and edited the paper. Mutaz A. Akkawi researched data and contributed to Introduction and Discussion. Abdelkareem A. Ashareef researched data and contributed to Introduction and Discussion. Zaher A. Almasri 
TABLE 4: Results of multivariate analysis for predictors of the TAS level.

\begin{tabular}{|c|c|c|c|c|c|}
\hline Source & & $\begin{array}{c}\text { Adjusted TAS } \\
\text { Mean } \pm \operatorname{SEM}(N)\end{array}$ & Sum of squares & $F$ & $P$ \\
\hline Corrected model & & & $22.415^{\mathrm{a}}$ & 2.934 & 0.000 \\
\hline Intercept & & & 4.130 & 7.027 & 0.008 \\
\hline \multirow{2}{*}{ Diabetic status } & Control & $2.020 \pm 0.075(195)$ & \multirow{2}{*}{2.735} & \multirow{2}{*}{4.653} & \multirow{2}{*}{0.032} \\
\hline & Diabetic & $1.896 \pm 0.060(197)$ & & & \\
\hline \multirow{4}{*}{ Education } & Illiterate & $2.064 \pm 0.101(68)$ & \multirow{4}{*}{5.089} & \multirow{4}{*}{2.887} & \multirow{4}{*}{0.036} \\
\hline & Less than high school & $2.059 \pm 0.060$ & & & \\
\hline & High school & $1.943 \pm 0.116(49)$ & & & \\
\hline & Diploma and above & $1.765 \pm 0.108(62)$ & & & \\
\hline \multirow{2}{*}{ Family history for diabetes } & Present & $1.978 \pm 0.061(222)$ & \multirow{2}{*}{0.039} & \multirow{2}{*}{0.067} & \multirow[t]{2}{*}{0.796} \\
\hline & Absent & $1.938 \pm 0.075(150)$ & & & \\
\hline \multirow{2}{*}{ Family history for CVD } & Present & $2.032 \pm 0.070(165)$ & \multirow{2}{*}{1.848} & \multirow{2}{*}{3.145} & \multirow{2}{*}{0.077} \\
\hline & Absent & $1.884 \pm 0.064(207)$ & & & \\
\hline Systolic BP & & & 0.892 & 1.518 & 0.219 \\
\hline BMI & & & 0.906 & 1.542 & 0.215 \\
\hline
\end{tabular}

${ }^{\mathrm{a}} R$ squared $=0.096$ (adjusted $R$ squared $=0.063$ ).

Analysis was performed using univariate general linear model (ANCOVA) as the potential predictors included categorical and continuous variables. TAS level was assessed as the dependent variable. Only variables that were significantly associated with TAS in the univariate analysis were included in the model. CVD: cardiovascular disease; BMI: body mass index; BP: blood pressure.

researched data. Khaldoun A. Bader was responsible for statistical analysis and reviewed and edited the paper. Umaiyeh M. Khammash supervised the staff at UNRWA clinics.

\section{Acknowledgments}

This project was partially supported by UNRWA. The authors thank Maysoon Obeidi and Dr. Khaled Alhilo from UNRWA for supervising the staff at UNRWA clinics and organizing the teams at three clinics. Also, the authors thank Qasem AbuRemeleh from Al-Quds University for his technical assistance in sample preparation and TAS assay. Akram T. Kharroubi is the guarantor.

\section{References}

[1] J. E. Shaw, R. A. Sicree, and P. Z. Zimmet, "Global estimates of the prevalence of diabetes for 2010 and 2030," Diabetes Research and Clinical Practice, vol. 87, no. 1, pp. 4-14, 2010.

[2] International Diabetes Federation, IDF Diabetes Atlas, International Diabetes Federation, Brussels, Belgium, 6th edition, 2013.

[3] H. F. Abdul-Rahim, A. Husseini, E. Bjertness, R. Giacaman, N. H. Gordon, and J. Jervell, "The metabolic syndrome in the West Bank population: an urban-rural comparison,” Diabetes Care, vol. 24, no. 2, pp. 275-279, 2001.

[4] H. F. Abdul-Rahim, A. Husseini, R. Giacaman, J. Jervell, and E. Bjertness, "Diabetes mellitus in an urban Palestinian population: prevalence and associated factors," Eastern Mediterranean Health Journal, vol. 7, no. 1-2, pp. 67-78, 2001.

[5] M. Malik, A. Bakir, B. Abi Saab, G. Roglic, and H. King, "Glucose intolerance and associated factors in the multi-ethnic population of the United Arab Emirates: results of a national survey," Diabetes Research and Clinical Practice, vol. 69, no. 2, pp. 188-195, 2005.
[6] H. Saadi, S. G. Carruthers, N. Nagelkerke et al., "Prevalence of diabetes mellitus and its complications in a population-based sample in Al Ain, United Arab Emirates," Diabetes Research and Clinical Practice, vol. 78, no. 3, pp. 369-377, 2007.

[7] A. Husseini, N. M. Abu-Rmeileh, N. Mikki et al., "Cardiovascular diseases, diabetes mellitus, and cancer in the occupied Palestinian territory," The Lancet, vol. 373, no. 9668, pp. 10411049, 2009.

[8] M. Brownlee, "Biochemistry and molecular cell biology of diabetic complications," Nature, vol. 414, no. 6865, pp. 813-820, 2001.

[9] I. C. West, "Radicals and oxidative stress in diabetes," Diabetic Medicine, vol. 17, no. 3, pp. 171-180, 2000.

[10] D. Giugliano, A. Ceriello, and G. Paolisso, "Oxidative stress and diabetic vascular complications," Diabetes Care, vol. 19, no. 3, pp. 257-267, 1996.

[11] P. Newsholme, E. P. Haber, S. M. Hirabara et al., "Diabetes associated cell stress and dysfunction: role of mitochondrial and non-mitochondrial ROS production and activity," Journal of Physiology, vol. 583, part 1, pp. 9-24, 2007.

[12] R. Rahimi, S. Nikfar, B. Larijani, and M. Abdollahi, "A review on the role of antioxidants in the management of diabetes and its complications," Biomedicine and Pharmacotherapy, vol. 59, no. 7, pp. 365-373, 2005.

[13] P. Rösen, P. P. Nawroth, G. King, W. Möller, H.-J. Tritschler, and L. Packer, "The role of oxidative stress in the onset and progression of diabetes and its complications: a summary of a Congress Series sponsored by UNESCO-MCBN, the American Diabetes Association and the German Diabetes Society," Diabetes/Metabolism Research and Reviews, vol. 17, no. 3, pp. 189212, 2001.

[14] A. M. Vincent, J. W. Russell, P. Low, and E. L. Feldman, "Oxidative stress in the pathogenesis of diabetic neuropathy," Endocrine Reviews, vol. 25, no. 4, pp. 612-628, 2004. 
[15] F. Giacco and M. Brownlee, "Oxidative stress and diabetic complications," Circulation Research, vol. 107, no. 9, pp. 10581070, 2010.

[16] A. C. Maritim, R. A. Sanders, and J. B. Watkins III, "Diabetes, oxidative stress, and antioxidants: a review," Journal of Biochemical and Molecular Toxicology, vol. 17, no. 1, pp. 24-38, 2003.

[17] A. A. Elmarakby and J. C. Sullivan, "Relationship between oxidative stress and inflammatory cytokines in diabetic nephropathy," Cardiovascular Therapeutics, vol. 30, no. 1, pp. 49-59, 2012.

[18] I. Hwang, J. Lee, J. Y. Huh et al., "Catalase deficiency accelerates diabetic renal injury through peroxisomal dysfunction," Diabetes, vol. 61, no. 3, pp. 728-738, 2012.

[19] A. Naudi, M. Jove, V. Ayala et al., "Cellular dysfunction in diabetes as maladaptive response to mitochondrial oxidative stress," Experimental Diabetes Research, vol. 2012, Article ID 696215, 14 pages, 2012.

[20] T. Coyne, T. I. Ibiebele, P. D. Baade et al., "Diabetes mellitus and serum carotenoids: findings of a population-based study in Queensland, Australia," American Journal of Clinical Nutrition, vol. 82, no. 3, pp. 685-693, 2005.

[21] S. R. J. Maxwell, H. Thomason, D. Sandler et al., "Antioxidant status in patients with uncomplicated insulin-dependent and non-insulin-dependent diabetes mellitus," European Journal of Clinical Investigation, vol. 27, no. 6, pp. 484-490, 1997.

[22] E. C. Opara, E. Abdel-Rahman, S. Soliman et al., "Depletion of total antioxidant capacity in type 2 diabetes," Metabolism: Clinical and Experimental, vol. 48, no. 11, pp. 1414-1417, 1999.

[23] F. Song, W. Jia, Y. Yao et al., "Oxidative stress, antioxidant status and DNA damage in patients with impaired glucose regulation and newly diagnosed type 2 diabetes," Clinical Science, vol. 112, no. 11-12, pp. 599-606, 2007.

[24] E. Véricel, C. Januel, M. Carreras, P. Moulin, and M. Lagarde, "Diabetic patients without vascular complications display enhanced basal platelet activation and decreased antioxidant status," Diabetes, vol. 53, no. 4, pp. 1046-1051, 2004.

[25] A. Picchi, S. Capobianco, T. Qiu et al., "Coronary microvascular dysfunction in diabetes mellitus: a review," World Journal of Cardiology, vol. 2, no. 11, pp. 377-390, 2010.

[26] C. Dominguez, E. Ruiz, M. Gussinye, and A. Carrascosa, "Oxidative stress at onset and in early stages of type 1 diabetes in children and adolescents," Diabetes Care, vol. 21, no. 10, pp. 1736-1742, 1998.

[27] F. Kimura, G. Hasegawa, H. Obayashi et al., "Serum extracellular superoxide dismutase in patients with type 2 diabetes: relationship to the development of micro- and macrovascular complications," Diabetes Care, vol. 26, no. 4, pp. 1246-1250, 2003.

[28] R. Srivatsan, S. Das, R. Gadde et al., "Antioxidants and lipid peroxidation status in diabetic patients with and without complications," Archives of Iranian Medicine, vol. 12, no. 2, pp. 121-127, 2009.

[29] Ş. Palanduz, E. Ademoğlu, C. Gökkuşu, and Ş. Tamer, "Plasma antioxidants and type 2 diabetes mellitus," Research Communications in Molecular Pathology and Pharmacology, vol. 109, no. 5-6, pp. 309-318, 2001.

[30] N. H. Al-Rawi, "Oxidative stress, antioxidant status and lipid profile in the saliva of type 2 diabetics," Diabetes and Vascular Disease Research, vol. 8, no. 1, pp. 22-28, 2011.

[31] M. P. Cabrera and R. H. Chihuailaf, "Antioxidants and the integrity of ocular tissues," Veterinary Medicine International, vol. 2011, Article ID 905153, 8 pages, 2011.
[32] R. P. Robertson, J. Harmon, P. O. Tran, Y. Tanaka, and H. Takahashi, "Glucose toxicity in $\beta$-cells: type 2 diabetes, good radicals gone bad, and the glutathione connection," Diabetes, vol. 52, no. 3, pp. 581-587, 2003.

[33] F. J. Pashkow, "Oxidative stress and inflammation in heart disease: do antioxidants have a role in treatment and/or prevention?" International Journal of Inflammation, vol. 2011, Article ID 514623, 9 pages, 2011.

[34] J. S. Johansen, A. Harris, D. Rychly, and A. Ergul, "Oxidative stress and the use of antioxidants in diabetes: linking basic science to clinical practice," Cardiovascular Diabetology, vol. 4, no. 1, article 5, 2005.

[35] H. Kaneto, Y. Kajimoto, J.-I. Miyagawa et al., "Beneficial effects of antioxidants in diabetes: possible protection of pancreatic $\beta$ cells against glucose toxicity," Diabetes, vol. 48 , no. 12 , pp. 2398 2406, 1999.

[36] A. Korkmaz, S. Ma, T. Topal, S. Rosales-Corral, D.-X. Tan, and R. J. Reiter, "Glucose: a vital toxin and potential utility of melatonin in protecting against the diabetic state," Molecular and Cellular Endocrinology, vol. 349, no. 2, pp. 128-137, 2012.

[37] M. Nebbioso, M. Federici, D. Rusciano, M. Evangelista, and N. Pescosolido, "Oxidative stress in preretinopathic diabetes subjects and antioxidants," Diabetes Technology \& Therapeutics, vol. 14, no. 3, pp. 257-263, 2012.

[38] S. Porasuphatana, S. Suddee, A. Nartnampong, J. Konsil, B. H. B.Pharm, and A. Santaweesuk, "Glycemic and oxidative status of patients with type 2 diabetes mellitus following oral administration of alphalipoic acid: a randomized double-blinded placebocontrolled study," Asia Pacific Journal of Clinical Nutrition, vol. 21, no. 1, pp. 12-21, 2012.

[39] P. H. Whiting, A. Kalansooriya, I. Holbrook, F. Haddad, and P. E. Jennings, "The relationship between chronic glycaemic control and oxidative stress in type 2 diabetes mellitus," British Journal of Biomedical Science, vol. 65, no. 2, pp. 71-74, 2008.

[40] S. Dewanjee, A. Maiti, R. Sahu, T. K. Dua, and V. Mandal, "Effective control of type 2 diabetes through antioxidant defense by edible fruits of Diospyros peregrina," Evidence-Based Complementary and Alternative Medicine, vol. 2011, Article ID 675397, 7 pages, 2011.

[41] B. Garcia-Bailo, A. El-Sohemy, P. S. Haddad et al., "Vitamins $\mathrm{D}, \mathrm{C}$, and $\mathrm{E}$ in the prevention of type 2 diabetes mellitus: modulation of inflammation and oxidative stress," Biologics: Targets and Therapy, vol. 5, pp. 7-19, 2011.

[42] L. A. da Costa, B. García-Bailo, A. Badawi, and A. El-Sohemy, "Genetic determinants of dietary antioxidant status," Progress in Molecular Biology and Translational Science, vol. 108, pp. 179200, 2012.

[43] A. Prathapan, S. V. Nampoothiri, S. Mini, and K. G. Raghu, "Antioxidant, antiglycation and inhibitory potential of Saraca ashoka flowers against the enzymes linked to type 2 diabetes and LDL oxidation," European Review for Medical and Pharmacological Sciences, vol. 16, no. 1, pp. 57-65, 2012. 


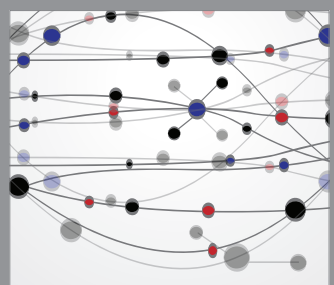

The Scientific World Journal
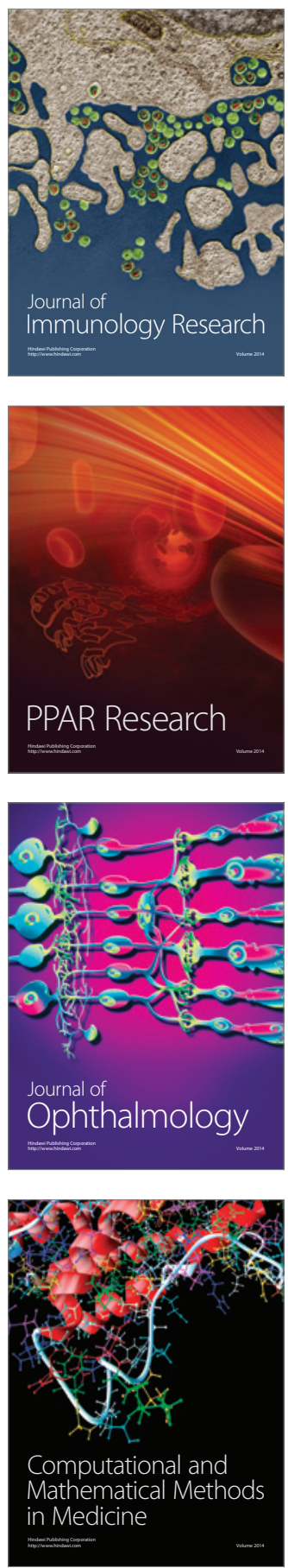

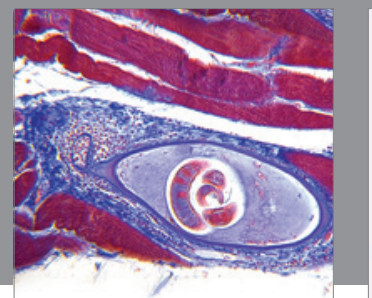

Gastroenterology

Research and Practice
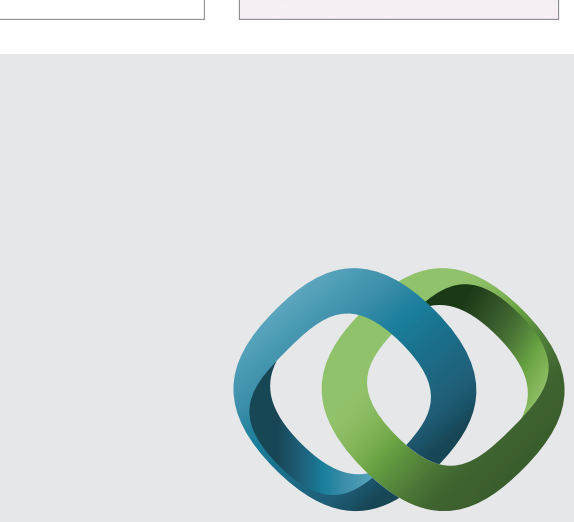

\section{Hindawi}

Submit your manuscripts at

http://www.hindawi.com
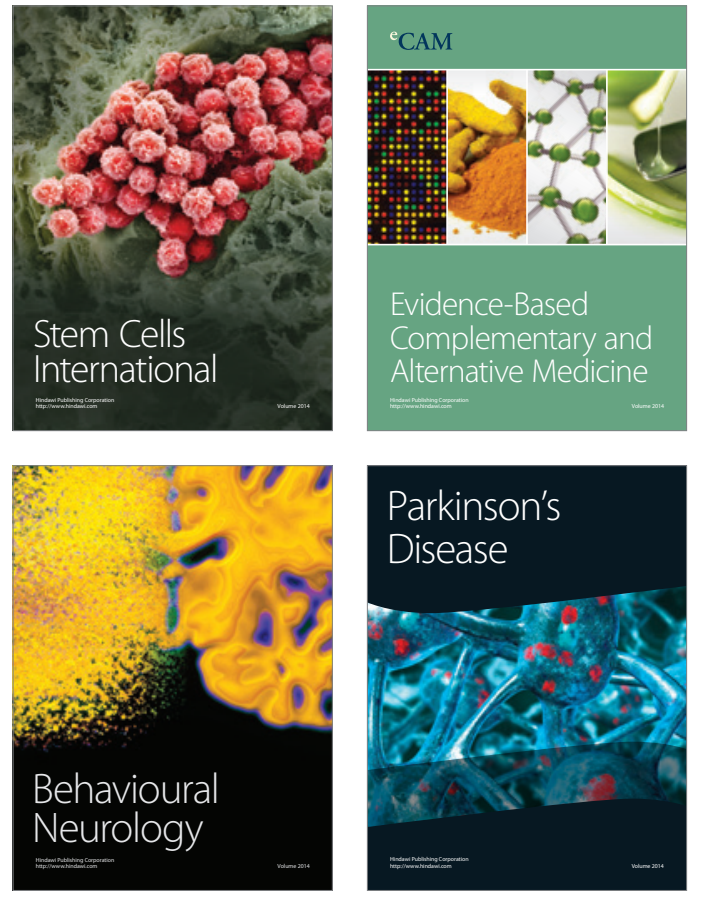
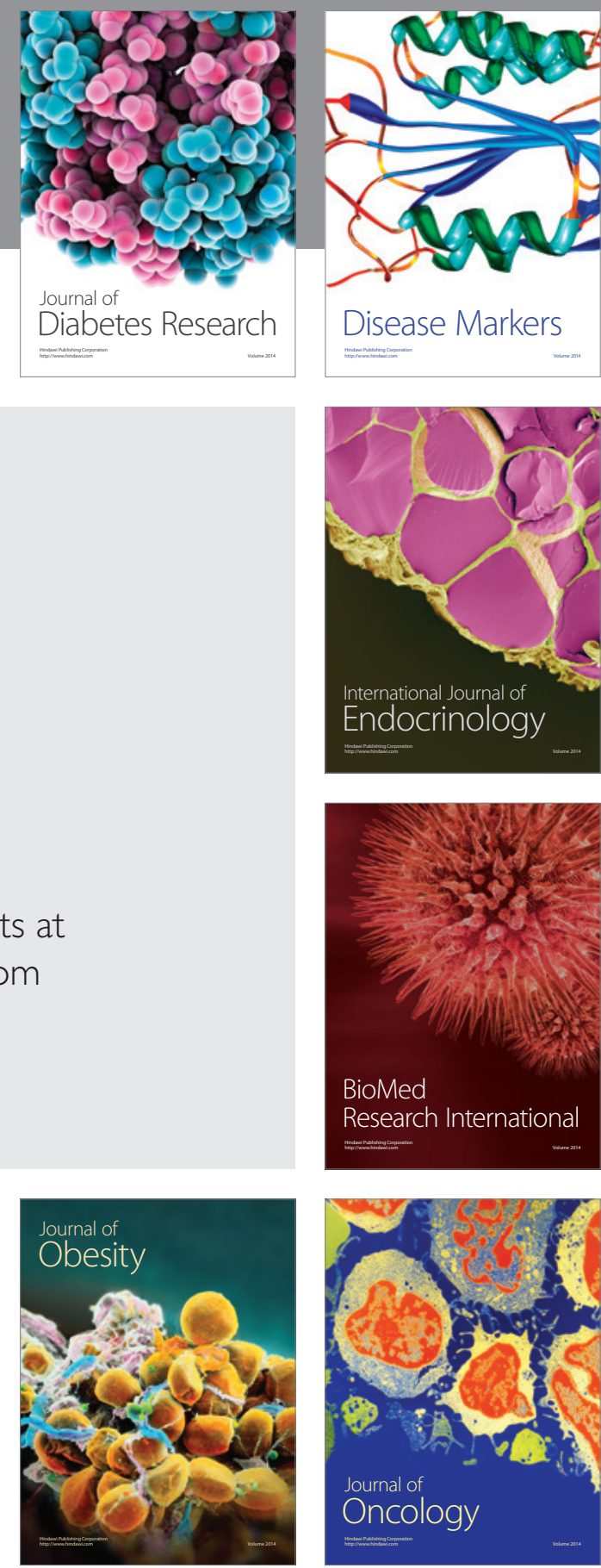

Disease Markers
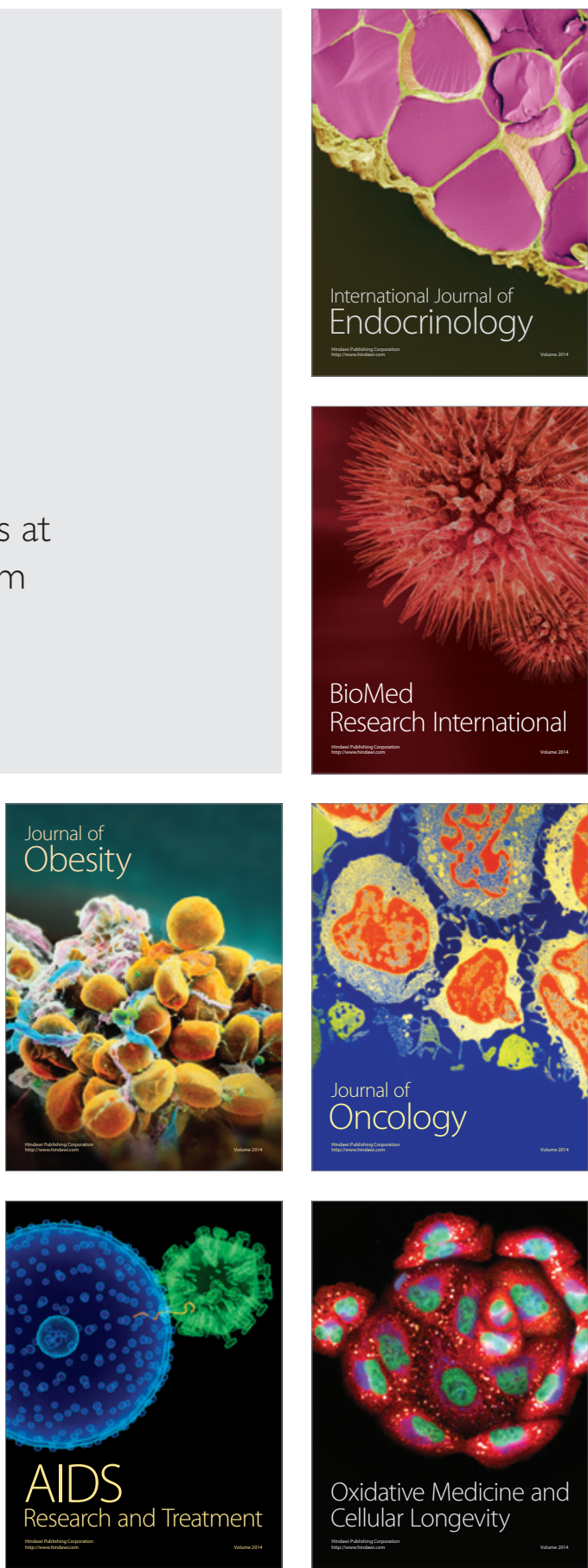